\title{
Rapport Between Training and Job Satisfaction: A Study on Influential Actors and Factors
}

\author{
Alvy Riasat Malik ${ }^{*} \quad$ Sabikun Nahar Bipasha² \\ 1.Associate Professor, Department of Human Resource Management, Jatiya Kabi Kazi Nazrul Islam University, \\ Trishal, Mymensingh-2220, Bangladesh \\ 2.Lecturer, Department of Marketing, Comilla University, Kotbari, Cumilla-3506, Bangladesh
}

\begin{abstract}
Training becomes an imperative variable of employees' performance and retention from the very beginning of the industrial revolution. However, with the passage of time training turns into an essential component of job satisfaction. Keeping this view in mind, the study aimed at identifying the interconnection between training and job satisfaction which ultimately plays a great role in attaining the goals of organization to a large scale. The study also attempts to recommend ways of instituting positive relations between training investment and job satisfaction. Information from secondary sources has been gathered and analysed to find out the affiliation between the two. Interestingly it has been revealed that training not only improves employee's morale and performance but also acts as a great contributing factor to employee retention and satisfaction.
\end{abstract}

Keywords: Training, Job satisfaction, Employee Retention, Training Investment

DOI: $10.7176 / \mathrm{EJBM} / 13-16-06$

Publication date:August $31^{\text {st }} 2021$

\section{Introduction}

To survive in today's fast-paced economy, every firm needs to have highly satisfied and skilled personnel. Employee job satisfaction and work performance have received a lot of attention from policymakers in recent years. To boost employee satisfaction level companies are using a variety of methods and instruments (Jones et al., 2009). Implementing training and development is believed to be one of the most important tools to improve workforce utilization and, thereby, potentially uplifting job satisfaction. Through investing in training, organizations wish to have confident, motivated and performing employees. Personnel training is considered to be a significant factor in a company's long-term success and employee development (Guest, 1997). Henceforth, it has become an integral part of the company's human resource department to polish and nourish the skills and concepts of employees in order to help them by correcting their deficiencies in performance and thereby motivating them to stay.

Studies over the years also claimed training to be a major building block to improve workforce satisfaction and performance. However, organizations should justify their investment in training programs by measuring training efficacy and return. So, the aim of this article is to see if employee training has a direct or indirect influence on job satisfaction, and if so, how training and job satisfaction are correlated. The study also tries to examine how organizations should design and implement training programs in order to get a higher return on investment in the forms of greater employee satisfaction.

\section{Objectives}

a. To explore rapport between training and job satisfaction.

b. To explore ways of instituting positive relations between training investment and job satisfaction.

\section{Methodology}

The study has been made with content analysis. Hence, the study is descriptive and exploratory in nature. Relevant information from secondary sources has been gathered and analysed to explore influential determinant factors of training and job satisfaction.

\section{Literature Review}

4.1 Training and Development

Training is an integral part of a company's human resource department (Weil and Woodall, 2005). Over the years training and development has been at the core of numerous research considerations by the scholars (Gorden, 1992). Armstrong (2001) and Craig (1987) outlined training as the formal and planned adjustment of behaviour, knowledge, attitude and action through systematic learning. Usually, these types of learning are materialized through education, coaching and planned experiences under the supervision of the facilitators. Swanson and Holton (2001) studied training and development as a systematic process to develop knowledge and work-related expertise through learning experiences to achieve better organizational performance. In fact, training programs are designed to equip the workers with job-related knowledge and skills to perform job duties 
effectively. To implement a successful training program HR managers should design a training framework by conducting the training needs analysis to determine suitable training needs for their employees (McCourT \& Derek, 2003). A well-designed training program offers several benefits. Khan et al. (2011) emphasized training as an important factor in business as it expands the competence and effectiveness of both employers and employees in the organization. Reynolds and Monica (2004) pointed out training as a comprehensive and allpervasive people development solution. Coleman (1990) suggested that either way both training and development aims at enhancing employee growth and satisfaction. Today organizations are offering a varied range of general and industry-specific training to their workforce. Regardless of the training type, training programs should focus on employee's need recognition, building the core learning abilities and long-term employability (Jackson and Schuler, 1995). Armstrong (2009) clearly expressed in his book that organizations may gain from training and development through winning the "heart and minds" of their workers so that workers can produce top performance with the drive to stay in the organization. Also, the quality and quantity of training, degree of management involvement, matching employee needs with specific training program, training delivery methods and styles act as influencing factors for a training program to have positive effects on organizational goal fulfilment (Cole, 2002).

\subsection{Impact of Training on Job Satisfaction}

Job satisfaction is defined as "how people feel about different aspects of their jobs as well the extent to which people like or dislike their jobs" (Spector, 1997, p. 2). In fact, it is a positive feeling of satisfaction an individual derives from his/her job. Employees have certain job values in mind when they arrive in the organization. Fulfilment of those job values result in pleasant emotion among them. However, if the job values are being neglected and unnoticed employees become frustrated and demotivated (Angeline, 2011). It has been well proven and tested that satisfied employees always perform better. Henceforth, to survive in the competitive business world, companies aim to have more happy employees. A good number of investigations, studies and reviews have been made to discover whether a firm can satisfy its employees by delivering work-related training. Elnaga and Imran (2013) pointed out that an effective training program significantly increases employee's motivation and commitment towards job duties. Poulston (2008) identified that organizations could deploy the most powerful influence upon employees' job satisfaction through providing effective training. Between 1994 to 2001 , in a survey among a few organizations of 13 European countries, Siebern-Thomas (2005) found that job satisfaction inclined to go high in organizations where training was provided to the workers. A well-trained employee is more stable, career-focused, and loyal to the organization. Fruitful training programs are major motivating sources for employees to pursue a long career with the organization. (O'Connor, 2003). Another survey conducted by Lucentcare in the year 2000 among 271 network professionals revealed that the opportunity to learn, acquire and absorb new skills and knowledge was the most important issue in job happiness (Blum and Kaplan, 2000). In fact, people always aspire to work for companies that require higher training, expertise and performance. In a European survey, it was observed that the ambition of involvement in High Performance Work Organisations (HPWOs) was linked with higher job satisfaction (Bauer, 2004). Training and development programs also boost employees' self-perceived abilities. It serves as a technique of improving employees' psychological well-being and mind-set and provides them the belief and confidence to operate effectively. Employees with high self-perceived abilities are more likely to be higher achievers than those with low selfperceived abilities (Arnolds and Boshoff, 2001). Employee turnover ratio also tends to rise with an organization's limited amount of training package as it is closely associated with employee dissatisfaction. Lack of training could possibly cause job dissatisfaction, high turnover and absenteeism which upsurges expenses and reduces the profitability of the companies in the long run (Kong et al., 2010). This link up with training, profitability and cost was analysed by Renee Barnett and Bradley in 2007. They examined that the majority of the workplace-related problems, conflicts and issues originated from employees with inadequate training as they have less understanding and awareness about their job scope, obligations and responsibilities. Renee Barnett and Bradley concluded that training could lead companies to save more money by having a more stable, confident and motivated group of workers. According to Egan, Yang, and Bartlett (2004), organizational learning and development culture reduces employee's willingness to leave an organization. Even when assessing which jobs to choose from, today's employees prefer jobs that offer better training and growth opportunities. In 2001, a study conducted by Ranstad (a personnel recruitment agency) among 2600 American and Canadian workers found that $80 \%$ of the respondents' primary motivation for accepting a job is the possibility of acquiring contemporary skills. (Schmidt, 2007). In a poll, Xerox employees in the European Business Service Centre ranked learning and education as the number one crucial aspect for continuing their employment relationship. A survey conducted by Wen, Muthuveloo, and Ping (2018) among Malaysian millennials working in international corporations in Malaysia revealed that there is a favourable association between job satisfaction and career development. Their research further revealed that young workers find satisfaction in receiving training as they see it as a key component for future career progress and growth. Also, it increases the possibility of young 
workers staying with the organization and being committed (Craig, Kimberly, and Bouchikhi, 2002). According to a behavioral survey conducted by Klein and Weaver (2000), orientation training programs increase the satisfaction of new employees by assisting them in becoming socialized and familiar with the work environment. Senior staff, on the other hand, found greater satisfaction in mentoring programs that involve a reciprocal way of tutoring and learning with newcomers. (Traut, Larson, and Fiemer, 2000). So, in providing training a generation gap stands in the way. Different types and patterns of training may have diverse impacts upon different age groups of employees. Another study regarding training and its impact by Mathieu, Tannenbaum and Salas (1991) discovered that depending on its ability to meet trainees' expectations and needs, training can have both positive or negative effects on employee behaviour. Thus, the relationship between training and job satisfaction is not always straightforward. Particularly detrimental relationships occur when individuals are not free to choose their training, rather it is imposed on them. Furthermore, training may have an adverse impact on job satisfaction if co-workers in the same office receive more training than the individual. (Jones et al., 2009). Companies should, however, make every effort to offset all of these negative aspects of training with employee satisfaction. Knowing training needs, developing the right learning culture, understanding worker's value, attitude guarantees better return of training programs through ensuring employee satisfaction.

\subsection{Relations between training investment and job satisfaction}

For workforce development it's important to train employees which requires lots of effort and capital investment. It's a logical concern to compare between costs of executing a training program and financial gains from that training. Analysis of return on training investment can help to identify the worthwhileness of training investment. Effective training investment increases an individual employee's productivity level that facilitates organizations with highly efficient and satisfied employees thus enhances organizational performance (Smith, 2001). Finegold et al. (2005) suggested that training investment along with flexible management support can lead to employee's recognition of organizational values and objectives and direct their efforts toward goals accomplishment. It is recognized that higher organizational and management support maximizes the employability of staff and generates employee satisfaction in return for training investment (José Chambel and Sobral, 2011). A metaanalysis by Tharenou, Saks and Moore (2007) on 67 previous studies advocated that training investments give the best return on human resource outcomes rather than organizational outcomes via improving employee attitudes and satisfaction. Training duration, methodology and relevant content are the major considerations while making training investments to get effective returns and generate job training satisfaction (Schmidt, 2007). The training investment is highly associated with organizational outcomes which stimulate employee's competencies and commitment to the organization when HR functions of the organization are strategically oriented (Choi and Yoon, 2015). Anwar, G., and Shukur, I. (2015) studied two research hypotheses on the private banking sector in Erbil and found that investment in training and employee development stimulates job satisfaction to a great extent. A study in the Telecom sector, Pakistan observed a $41.2 \%$ change in job satisfaction level and $61 \%$ in the performance level due to just one unit change in their training investment plan (Khan et al., 2016). Considering the training investment and return in terms of satisfaction, Price and Reichert (2017) identified that continuous investment on learning and education of nurses enhance their career growth opportunities and ensure job satisfaction. Study also showed that there is a significant association between training investment for career growth opportunities and employee satisfaction while considering remaining factors constant (Mulyadi, 2020). Dipietro (2006) found that positive behavioural changes are associated with investing in training methods. Investment in different training and development programs can stimulate positive changes within the organization but there is a need for a clear idea about the extent of changes which demands further study to figure out the best ways to get the return on training investment especially in forms of job satisfaction. However, it is quite evident that knowing training needs, developing the right learning culture, understanding worker's value and attitude guarantees better return of training programs through ensuring employee satisfaction.

\section{Discussion \& Analysis}

Returning to the main questions of this research, whether training and development has an influence on job satisfaction and how training investment can be maximized through ensuring satisfaction, this component of the paper focuses on diagnosing any relevancy or gaps between literature reviews (prior research efforts) and research questions. First, let us focus on the overall impacts of training and development. Most prior research have established clear and thorough evidence that T\&D programs have a comprehensive impact on an organization's growth and progress. Organizational growth is a vast notion that necessitates a significant amount of effort. And when any functions or ingredients of the organization has a beneficial influence on the overall development of the organization, the explanations have to be multifarious. So, what is it about training and development that has cranked up constant organizational development over the years? Let's examine the works of different researchers. Majority of the authors in their writings mentioned T\&D programs as a process that 
facilitates education and learning. Their analyses and surveys institutionalized the fact that this process of learning is intended to improve the skills, expertise, values, behaviours and norms of the workers. It is apparent that having the opportunity to learn new and improved skills, as well as being exposed to a positive learning culture increases employee happiness and motivation to perform better. And when employees are happy organizational success and progress is the subsequent outcome. Thus, the influence of training and development on employee and the organization as a whole can be thought of as a chain. Concentrating on the first question, how does training and job satisfaction link with each other; let's have a close review. The concept of 'job satisfaction' is subjective in nature. Because it is the feeling of an individual towards his/her work. This feeling is personal and influenced by individual tastes and ultimately varies from person to person. So, it is quite clear that factors or elements responsible for job satisfaction differ from person to person. What needs clarification is, if training is among one of these factors? Bringing together the reviews of the literature, the following possible correlation between training and job satisfaction can be drawn.

Training equips an individual with the expertise needed to perform their assigned jobs. This up-to-date knowledge and expertise acquired through training help employees to exercise their job duties and responsibilities with greater confidence. Beauchamp et al. (2005) recommended that the lesser the sense of role confusion and ambiguity among workers the higher their level of motivation. Furthermore, engaging in the process of continuous learning and development makes employees more confident about his/her career. As from the observations of different scholars, individuals who work in firms with an ongoing training culture have a higher level of career stability and certainty. The reasons are fairly evident. Well-trained employees recognize the fact that for them career advancement is much smoother both within the company and even outside of it as they have the necessary skills to flourish. Psychologically, it excels them to perform harder as well as improves their self-efficacy ratio, self-perceived competency level and accomplishment mentality. Behaviours and attitudes associated with workplace dissatisfaction such as; negligence, turnover, absenteeism, poor performance etc. tends to fall down among employees receiving well-designed training from their organizations. How can these attitudes and behaviours from the trained-up employees be explained? The proven fact is employees' low turnover rate and high-performance level is very much associated with having the scope to learn new skills from the organization. Apart from that, there are additional issues to be addressed. Several studies prescribed trained workers as being more socialized and having stronger mutual ties than others. An ongoing learning environment assists employees in becoming acquainted with a variety of interdepartmental work groups, allowing them to form interactive relationships with their co-workers. (Adkins, 1995). This raises the pledge and passion towards their colleagues, supervisors and organization as a whole, encouraging them to continue employment relations for a longer period of time. The following case studies will shed light further into the relationship between training and job satisfaction.

In 2009, Khalid Khan and Naveed Akhtar Baloch investigated a scenario on the influence of training and development in the behaviours of public accountants in Khyber Pakhtunkhwa, Pakistan. Before and after training behaviours of 322 trainee officers were monitored, and they were then asked about their reactions to being a part of training programs. The research resulted in a very specific outcome. Employee's responses were very positive and training programs have been demonstrated to have a significant effect on employees' value, behaviour, and satisfaction level. The case study also revealed that training enhances employees' perceptions of the organization and results in favourable psychological improvements. Let's analyze another viewpoint of workers regarding the influence of the training program shown by Nassazi in 2013. Following a series of training programs, 57 employees from Warid Telecom Uganda were asked about their realization. The majority of the respondents, $86.7 \%$, believed that the training methods used during training had an impact on their skills. Around half of those polled said that higher-quality, well-designed training programs have a greater influence on their performance. A case on Aston Martin, (a British car manufacturer) shows that the learning management team of the company aimed to ensure a flexible and electronic learning system for continuously improving the skills of the employees. Employee engagement surveys are conducted concurrently to ensure that its' T\&D programs can respond to any type of specific employee needs. The result indicates that this type of training approach fosters a sense of ownership among workers. It also enables employees to acquire fresh, more dynamic skills and talents. (Pratt, 2019).

All three of these cases are connected to the study's findings and serve as excellent illustrations of the impact of training and development programs on job satisfaction as well as the necessity of investing in T\&D. However, will only executing a T\&D program be enough to get the return on training investment? Concentrating on the second objective; to explore ways to get a higher return on training investment and maximize job satisfaction, let's consider the following scenarios.

Wen-Rou Huang (2020) explored the three best possible ways to get the best return on training investment and make the employees satisfied with their job: training needs assessment, designing and delivering training programs and evaluation of training. Needs assessment for training requires the determination of whether training is necessary or not (Noe, 2010). The purpose of a need assessment is to identify training gaps rather than 
any solution. Program design and delivery requires the formation and coordination of the whole training program. The idea behind program design is to make effective and efficient training events. Finally, an evaluation should be made addressing major issues such as feedback regarding attained training objectives and post-training employee job performance. The study demonstrated that to execute an effective training program and to make the return on training investment incorporated with job satisfaction, training needs assessment and evaluation of employee feedback are indispensable. Chiang, Back and Canter (2005) examined the training quality of the hotel industry in relation to job satisfaction and intention to stay. The study was conducted on four hotels in Missouri and Kansas and revealed that if there is a gap between employee's and supervisor's training perception and expectations it would give a minimum return on training investment. It was found that the mean of their training expectations was 5.89 whereas perception rated 5.44 on a 7 - point rating scale. Using a paired sample $\mathrm{t}$-test $(\mathrm{t}$ value was 4.87 and $\mathrm{P}$ value was less than 0.05 ) the study ended up with a conclusion that employee's training perceptions were meaningfully lower than that of their training expectations (Chiang, Back and Canter, 2005). Lower appealing training materials were identified as one of the main reasons for creating training expectations and perception gaps. The case also exhibited that more knowledgeable trainers could best help to make the training effective and generate a greater return on training investment. To assess training perceptions and expectations gap researchers also used the SERVQUAL model. Among its five dimensions, assurance (.93) was the most relevant dimension to minimize the gap and to get a better return on training investment. Assurance is associated with the trainer's level of understanding and ability to build trust. For maximizing return on training investment, assigning knowledgeable trainers and using appealing training materials help to stimulate employee job satisfaction and intention to stay. Another study by Lyau and Pucel (2008) can give insights about the ways to institute a positive association between training and job satisfaction. The study was on the manufacturing industry and figured out a noteworthy relationship between training investment and labor productivity. The result was justified with an example of Nabisco; it traced ten years' outcomes of training and analyzed the ways to transmit training experience into the real field. In the real field to get maximum return on training investment was possible while the whole training program ran under a strong management support system. The final result concluded that with the help of a strong management training support system around $\$ 20$ profit increased per dollar training investment (Lyau and Pucel, 2008). To maximize labor productivity using training investment it is essential to have strong management support. All these studies are relevant to the outcomes of this project and picturing the proper recommendations to maximize the return on training investment.

The above evaluation is giving a clear insight that corporates should make training needs assessment before conducting training programs and then evaluate employee's training feedback to stimulate job satisfaction. This will help to identify training gaps and will provide a clear picture of whether training experience is transmitted into the real field or not. In fact, before designing a training program, workers' psychological demands and differences should also be taken into consideration. A training program designed without understanding the needs and attitudes of the employees may have a diverse impact upon them. Employees vary greatly in terms of their needs, behaviour, age, etc. As job satisfaction or dissatisfaction both are related to human feelings, the HR department should construct training programs by matching with each employees' requirements. A mismatch between education and requirement could cause dissatisfaction. In order to be effective enough, training programs should also run under a strong training management support system which will help increase the return on training investment and labor productivity of the organization as well as employee job satisfaction. For maximizing job satisfaction through training investment, it is necessary to minimize training expectations and perception gaps by assigning knowledgeable trainers and relevant training content available to the trainee.

\section{Conclusion}

It has been recurrently argued in different studies that a happy employee is a productive employee. Training and job satisfaction play a very significant role in improving employees' morale, performance and job satisfaction. So, organizations should arrange periodic training programs with reputed trainers. However, factors like establishing a congenial environment of training, assessing training needs, evaluating performance before and after training and providing reward on performances in receiving training should be considered to make training successful. Special attention should also be given in launching innovative training. One important thing should bear in mind that training helps any organisation to achieve its required outcome, similarly, job satisfaction cannot be achieved without a planned training program. Therefore, it is the responsibility of the organization to create a planned well-decorated training program and also make a friendly environment so that the employee can execute their task effectively.

\section{References}

Adkins, C. L. (1995). Previous work experience and organizational socialization: A longitudinal examination. Academy of Management Journal, 38(3), 839-862.

Angeline, T. (2011). Managing generational diversity at the workplace expectations and perceptions of different 
generations expectations and perceptions of different generations. African Journal of Business Management, $5(2), 249-255$.

Anwar, G., \& Shukur, I. (2015). The Impact of Training and Development on Job Satisfaction: A Case Study of Private Banks in Erbil. International Journal of Social Sciences \& Educational Studies, 2 (1), 65-88.

Armstrong, M. (2001). Armstrong's Handbook of Human Resource Management Practice. $8^{\text {th }}$ ed. London: Kogan Page Limited.

Armstrong, M. (2009). Armstrong's Handbook of Human Resource Management Practice. 11 ${ }^{\text {th }}$ ed. London: Kogan Page Limited.

Arnolds, C.A., \& Boshoff, C. (2001). Psychological capital: A positive resource for combating employee stress and turnover. Human Resource Management, 48(5), 677-693.

Bauer, T.K. (2004). High performance workplace practices and job satisfaction: evidence from Europe. IZA Discussion Paper No. 1265, Bonn.

Beauchamp, M., Bray, S., Eys, M., \& Carron, A. (2005). Multidimensional Role Ambiguity and Role Satisfaction: A Prospective Examination Using Interdependent Sport Teams. Journal of Applied Social Psychology, 35(12), 2560-2576.

Blum, R., \& Kaplan, J. M. (2000). Network professionals' job satisfaction. Lucent Technologies Network Care, $52,16-28$.

Chiang, C., Back, K. and Canter, D., (2005). The Impact of Employee Training on Job Satisfaction and Intention to Stay in the Hotel Industry. Journal of Human Resources in Hospitality \& Tourism, 4(2), 99-118.

Choi, M. and Yoon, H., (2015). Training investment and organizational outcomes: a moderated mediation model of employee outcomes and strategic orientation of the HR function. The International Journal of Human Resource Management, 26(20), 2632-2651.

Cole, G.A. (2002). Personnel and human resource management, 5th Ed. Continuum London: York Publishers.

Coleman, J.S. (1990). Foundations of Social Theory. Cambridge, MA: Harvard University Press.

Craig, E., Kimberly, J., \& Bouchikhi, H. (2002). Can loyalty be leased? Harvard Business Review, 80(9), 24.

Craig, R. L. (1987). The ASTD training and development handbook: a guide to human resource development. New York, McGraw-Hill.

Dipietro, R., (2006). Return on Investment in Managerial Training. Journal of Foodservice Business Research, 7(4), 79-96.

Egan, T., Yang, B., and Bartlett, K. R. (2004). The effects of organizational learning culture and job satisfaction on motivation to transfer learning and turnover intention. Human Resource Development Quarterly, 15(3), 279-301.

Elnaga A., and Imran, A. (2013). The Effect of Training on Employee Performance. European Journal of Business and Management, 5(4), 137-147.

Finegold, D., Levenson, A. and VanBuren, M. (2005), "Access to training and its impact on temporary workers", Human Resource Management Journal, 15, 66-85.

Gordon, B. (1992). Are Canadian firms under investing in training? Canadian Business Economics, 1(1), $25-33$.

Guest, D. E. (1997). Human resource management and industrial relations. Journal of Management Studies, 24(5), 503-521.

Huang, W., 2020. Job Training Satisfaction, Job Satisfaction, and Job a Performance. Career Development and Job Satisfaction.

Jackson, S., and Schuler, R. (1995). Understanding Human Resource Management in the Context of Organizations and their Environments. Annual Review of Psychology, 46, 237-264.

Jones, M.K., Jones, R.J., Latreille, P.L., \& Sloane, P.J. (2009). Training, job satisfaction, and workplace performance in Britain: Evidence from WERS 2004. Labour, 23(1), 139-175.

José Chambel, M. and Sobral, F., (2011). Training is an investment with return in temporary workers. Career Development International, 16(2), 161-177.

Khan, A., Abbasi, S., Waseem, R., Ayaz, M. and Ijaz, M., (2016). Impact of Training and Development of Employees on Employee Performance through Job Satisfaction: A Study of Telecom Sector of Pakistan. Business Management and Strategy, 7(1), 29.

Khan, K., \& Baloch, N. A. (2009). Impact of Training on Employee Development and Other Behavioral Outcomes: A Case of Public Accountant Trainees in Khyber Pakhtunkhwa. Journal of Managerial Sciences, 11(1), 93-107.

Khan, R.I., Aslam, H.D. and Lodhi, I., (2011). Compensation Management: A strategic conduit towards achieving employee retention and Job Satisfaction in Banking Sector of Pakistan. International journal of human resource studies, $1(1), 89$.

Klein, H., \& Weaver, N. (2000). The effectiveness of an organizational - level orientation training program in the socialization of new hires. Personnel Psychology, 53(1), 47-66.

Kong, H., Cheung, C., and Zhang, H. (2010). Career management systems: what are China's stateowned hotels 
practicing? International Journal of Contemporary Hospitality Management, 22(4), 467-482.

Lyau, N. and Pucel, D., (2008). Economic Return on Training Investment at the Organization Level. Performance Improvement Quarterly, 8(3), 68-79.

Mathieu, J., Tannenbaum, S. I., \& Salas, E. (1991). Influences of individual and situational characteristics on measures of training effectiveness. The Academy of Management Journal, 35(4), 828.

McCourt, W., \& Derek, E. (2003). Global Human Resource Management: Managing People in Developing and Transitional Countries. Cheltenham, UK: Edward Elgar.

Mulyadi, F., (2020). The Influence of Training and Career Development on Employee Job Satisfaction. Almana : Jurnal Manajemen dan Bisnis, 4(2), 290-296.

Nassazi, A. (2013). Effects of Trainings on Employee Performance: Evidence from Uganda. Business Economics and Tourism, University of Applied Sciences. Retrieved from https://core.ac.uk/download/pdf/38098025.pdf

Noe RA. (2010) Employee Training and Development. 5th ed. New York: McGraw-Hill; 589p

O'Connor, N. (2003). Career Success in Training \& Development: Is It What You Know or Who You Know? Performance Improvement Quarterly, 16(3), 5-16.

Poulston, J. (2008). Hospitality workplace problems and poor training: a close relationship. International Journal of Contemporary Hospitality Management, 20(4), 412-427.

Pratt, L., (2019). HR Distinction Spotlight: Aston Martin's organisational transformation journey - HRD. [online] HRD. Available at: <https://www.hrdconnect.com/2019/12/05/hr-distinction-spotlight-aston-martinsorganisational-transformation-journey/> [Accessed 3 July 2021].

Price, S. and Reichert, C., (2017). The Importance of Continuing Professional Development to Career Satisfaction and Patient Care: Meeting the Needs of Novice to Mid- to Late-Career Nurses throughout Their Career Span. Administrative Sciences, 7(2), 17.

Reynolds, A. S., and Monica, J. R. (2004). The Training and Development Strategic Plan Workbook.

Schmidt, S. (2007). The relationship between satisfaction with workplace training and overall job satisfaction. Human Resource Development Quarterly, 18(4), 481-498.

Siebern-Thomas, F. (2005). Job quality in European labour markets, in Bazen S., Lucifora C. and Salverda W. (Eds.), Job Quality and Employer Behaviour, Palgrave Macmillan, Basingstoke, Hants, 31-66.

Smith, A., (2001). Return on Investment in Training. National Centre for Vocational Education Research, Leabrook (Australia), p.121. Distributed by ERIC Clearinghouse.

Spector, P. E. (1997). Job satisfaction application, assessment, cause, and consequences. Thousand Oaks, Calif.; London: SAGE.

Swanson, R. A., Holton, E. F. (2001). Foundations of Human Resource Development. San Franciso: BerrettKoehler.

Tharenou, P., Saks, A. and Moore, C., 2007. A review and critique of research on training and organizationallevel outcomes. Human Resource Management Review, 17(3), 251-273.

Traut, C. A., Larsen, R., \& Fiemer, S. H. (2000). Hanging on or fading out. Public Personnel Management, 29(3), 343.

Weil, A., \& Woodall, J. (2005). HRD in France: the corporate perspective. Journal of European Industrial Training, 29(7), 529-540.

Wen, C., Muthuveloo, R., and Ping, T. A. (2018). Factors Influencing Job Satisfaction: A Perspective of Millennials in Malaysia Multinational (MNC) Companies. Global Business and Management Research, $10(1), 48-66$. 